\title{
Advanced Academic Writing Course for International Students Belonging to "One Belt, One Road"
}

\author{
Chang Chen*, Habiba Khalid, and Farrukh Raza Amin \\ College of Chemical Engineering \\ Beijing University of Chemical Technology \\ Beijing, China
}

\begin{abstract}
China has attracted many international students in the past five years through Chinese Scholarship Council (CSC) to improve the standard of higher education and research productivity. Most of the students come from "One belt, One Road" countries to pursue master and doctoral degrees. The School of International Education and Graduate School at Beijing University of Chemical Technology (BUCT), China implemented Advanced Academic Writing Skills (AAWS) as a mandatory course for non-native English-speaking students, belonging to One Belt, One Road (OBOR), to enable them to improve and polish their academic writing skills. The ultimate goal of this paper is to critically investigate student's perception of the AAWS mandatory course to improve their academic writing skills. Formative and summative assessments and student perceptions were used to assess the student satisfaction and knowledge. An evaluation index was administered to collect student perceptions about the course. Students reported a high degree of satisfaction with the course, indicating that the course was well-designed and implemented. The results provided a model to other universities to bring adjustments for the improvement of the academic writing skills of young researchers, and comprehensively improve the quality of research and publications worldwide.
\end{abstract}

Keywords: Academic writing; One belt, One Road; Research productivity; Research quality; Critical thinking; Graduate writing.

\section{Introduction}

Dissemination of knowledge is essential for the growth of any academic field and publishing scholarly work is highly expected from the people working within academia (Morton, 2013; Uçar \& Yazıc1, 2016). Publication not only 
measures the research productivity necessary for promotion and performance review but is regarded as a professional obligation (Langum \& Sullivan, 2017; Moussa-inaty, 2017). Many scientists have busy schedules, due to which they procrastinate the task of scientific and academic writing. Furthermore, some scientists and researchers have not developed the habit of writing on a regular basis and therefore, have inadequate academic writing skills. Others might have skills for writing a term paper, acquired from their past educational experience but do not exactly know how to submit an impressive piece of writing to a professional journal. Thus, academic writing is perceived to be a difficult and painful task for many researchers and scientists, such that it reaches to the point of being completely neglected. Some studies have mentioned the obstacles faced by researchers belonging to different disciplines in publishing valuable scientific work, however, there is a very little evidence of the successful implementation of various initiatives in general academia to improve students' writing skills (Casañ-pitarch \& Calvo-ferrer, 2015; Eaton, 2017; Klimova, 2013; Rakedzon \& Baram-tsabari, 2017). Countries with a well-established education system focus on writing courses coupled with group writing activities that divide the workload and promote joint authorship of a publishable work (Ness, Duffy, Mccallum, \& Price, 2014).

However, the countries seeking a better repute in the provision of quality research are becoming more focused on polishing the academic writing skills of young researchers and scientists. China has attracted a great number of international students in the past five years through Chinese Scholarship Council (CSC) to improve the higher education and research productivity in the country. Most of the students come from countries alongside the Silk Road Economic Belt and the 21st-Century Maritime Silk Road, which links China to Europe, through Central and Western Asia, and connects China and Southeast Asian countries via the sea to Africa and Europe. The routes are jointly referred to as the "One Belt, One Road" (OBOR) (Sheu \& Kundu, 2017). The international students pursuing master and doctoral programs at Beijing University of Chemical Technology (BUCT), China belong to Uzbekistan, Kyrgyzstan, Tajikistan, Kazakhstan, Pakistan, Turkmenistan, Senegal, Iran, Afghanistan, Korea, Myanmar, Yemen, Thailand, Somalia, and Russia (Ejdys, 2017; Marsden, 2017). In November 2016, the School of International Education and Graduate School at BUCT approved Advanced Academic Writing Skills (AAWS) as a mandatory course for multi-ethnic and multilingual, non-native English speaking students coming from all the above-mentioned countries, to enable them to improve their academic writing skills. Although these students have been trained in English for 10-18 years, they still have poor academic writing skills, which need to be improved. The significance of the course is to enable the students to get started with writing different types of research papers and improve the quality of an already prepared manuscript.

Besides, the course is significant in improving the international education of BUCT with the accompanying objective of increasing publication success rates. Thus, the course was subsequently opened to master and doctoral students in 2017, as a first trial session. This mandatory course had meticulously designed chapters to broaden students' perspective regarding academic writing and to enable them to avoid writing errors. AAWS might be useful for students coming 
from OBOR countries, as they are connected globally and have more chances to exchange the research ideas in future and train more students in their respective countries.

The specific objectives of this study are to (a) describe the design and implementation of this two-credit academic writing course (b) assess the experience of participants in the course, its effectiveness and usefulness, and how it influenced their peer-reviewing and writing skills.

\section{Educational activity}

In the curriculum used at BUCT, each course is offered once during an academic year. The number of credit hours assigned to a course depends on the duration of the course, just as in most other academic institutions. For example, a twocredit course in a traditional program is equivalent to 32 instructional hours, (16 weeks, two hours each week). Keeping it in consideration, the nature and duration of the elective course "Advanced Academic Writing Skills" is rather unique.

AAWS serves as an introduction to the academic writing in various fields of sciences such as Biochemistry, Organic Chemistry, Microbiology, Computer Sciences, Material Sciences, Mechanical Engineering, Chemical Engineering, and Environmental Engineering. The course includes both classroom activities and volunteer presentations on the use of different software mentioned in the "Sample course activity section".

\section{Sample of course schedule}

The course requires 32 hours of classroom. The specific expectations are provided by the instructor of the course. An example of a class schedule is provided in Table 1. 
Table 1. An Example of Class Schedule in AAWS

\begin{tabular}{|c|c|c|}
\hline Chapters & Title & Learning Objectives \\
\hline 1 & Introduction & $\begin{array}{l}\text { To motivate students to be all-rounded researchers and scientists. } \\
\text { To enable students to identify their research problems. }\end{array}$ \\
\hline 2 & $\begin{array}{l}\text { Importance and Characteristics of Scientific } \\
\text { Paper }\end{array}$ & $\begin{array}{l}\text { To learn the scope and importance of academic writing. } \\
\text { To learn the difference between academic writing and other writings. }\end{array}$ \\
\hline 3 & $\begin{array}{l}\text { Principles and Grammar in Writing/Class } \\
\text { practice related with correcting grammar } \\
\text { and logic of the manuscript }\end{array}$ & $\begin{array}{l}\text { To learn the most important key points of a standard manuscript such as novelty, } \\
\text { significance, clarity, organizing ideas logically, using appropriate scientific } \\
\text { language and meticulously working on the draft to ensure quality. } \\
\text { To learn to connect the logic tightly, while drafting a manuscript. } \\
\text { To learn the format/style and scientific language of the manuscript. } \\
\text { To practice some examples and improving the dexterity. }\end{array}$ \\
\hline 4 & Article Types/Class Presentations & $\begin{array}{l}\text { To learn the difference between research paper, full length/regular article, } \\
\text { review, mini-review, communication, notes, technical notes, reports, case study, } \\
\text { special issues, book review, announcement, and calendar. }\end{array}$ \\
\hline \multirow[t]{2}{*}{5} & \multirow[t]{2}{*}{$\begin{array}{l}\text { How to Submit to an Appropriate } \\
\text { Place?/Class Practice of submitting scientific } \\
\text { manuscript to the relevant journal, starting } \\
\text { from relevant journal search to final } \\
\text { submission }\end{array}$} & $\begin{array}{l}\text { To learn to select a conference or journal. } \\
\text { To learn different examples of different indexed sources such as Science Citation } \\
\text { Index (SCI), Engineering Index (EI), Index to Scientific \& Technical Proceedings } \\
\text { (ISTP) along with their development and calculation of Impact Factor (IF). }\end{array}$ \\
\hline & & $\begin{array}{l}\text { To understand a journal's true place in the research landscape and learning the } \\
\text { procedure of selecting a journal based on Web of Science data and Journal } \\
\text { Citation Report (JCR). }\end{array}$ \\
\hline \multirow[t]{2}{*}{6} & \multirow[t]{2}{*}{ How to Organize Main Structure? } & $\begin{array}{l}\text { Learning common structure for scientific paper starting from Title to Abstract, } \\
\text { Keywords, Introduction, Experimental part (Materials and methods), Results, } \\
\text { Discussion, Conclusions, Acknowledgment, Reference as well as properly going } \\
\text { through the instructions of the relevant journals for authors and artwork } \\
\text { instructions (instructions for creating illustrations). }\end{array}$ \\
\hline & & $\begin{array}{l}\text { Instructor of the course (HSS511E) has spent quality time in demonstrating the } \\
\text { drafting of each section with at least five examples each. }\end{array}$ \\
\hline
\end{tabular}

(C) 2017 The authors and IJLTER.ORG. All rights reserved. 

Graphing/Detailed volunteer presentations on the use of Origin, Excel, and SPSS Reference Managing/Detailed volunteer presentations on using Endnote and Mendeley

\section{Submission and Review Process}

Ethics \& Anti-Plagiarism
To learn to distinguish between high-quality versus low-quality tables, graphs, and other relevant illustrations and learn to create them using the different powerful softwares.

To learn managing references, principles of inserting in-text citations and creating a bibliography for a given manuscript.

A detailed presentation on the use of different reference managing softwares, (Mendeley and Endnote) introduced students to the most advanced features offered by softwares including creating their own template, creating an online library, and modifying the reference style as per the journal guidelines.

To learn three main barriers in the submission and review process; the first barrier is experimental design and data processing \& analysis; the second barrier is writing a quality draft and choosing the most relevant journal; the third barrier is strictly abiding by the author's instructions given by the journal, formatting and polishing the manuscript prior to submission. The instructor gave valuable solutions to the students to overcome these barriers.

To have insights into the submission and review process, which has four categories namely writing work, editorial work, review work, and publication work. Students were introduced to four potential outcomes of the mentioned process such as acceptance of the manuscript for publication, minor revision, major revision, and rejection with major concerns.

A checklist for authors, editors, and reviewers were provided to the students to know the process well.

To understand research ethics and issues such as conduct of individuals, research fraud, mistreatment of lab animals, accuracy and honesty in reporting results, plagiarism, violation of intellectual property rights and conflict of interests. In this course, students have learnt to overcome these issues.

Students were also informed of the serious repercussions of the unethical behavior during research. This would result in a more careful behavior on their part as researchers and scientists.

Students were introduced to different categories of plagiarism such as intentional plagiarism and unintentional plagiarism. Not only this, they were given some useful tips to avoid plagiarism in their work. 


\section{Sample of a course activity}

Since the students engaged in the course have diverse research backgrounds and are too numerous to describe here, we will provide a representative example of a student activity. One group of two students gave a one-hour presentation as volunteers regarding the use of graphing software, Origin 9.1. The students were asked to demonstrate interactive scientific graphing and data analysis. One group of two other students gave a detailed presentation on the use of Microsoft Excel to demonstrate commonly used functions such as constructing improved pivot tables, getting familiar with additional image editing capabilities, to use many new, most highly specialized formulas to improve accuracy and create multiple graphs. One group volunteered to give a detailed presentation on the use of SPSS for logical batched and non-batched statistical analysis. The presenter has also taken the other students through the procedure of creating multiple charts and graphs in SPSS.

One group of two students gave a one-hour presentation on the use of Mendeley, to demonstrate the reference management in the manuscript or any other academic piece of writing. The students introduced various concepts such as managing in-text citations, bibliography and creating the library in the software by adding the most relevant research articles germane to their research. The other group of two students who have taken the coursework were also introduced to advance features of powerful reference managing software, called "Endnote". The last group of two students gave a detailed presentation on managing different reference styles and creation of their own reference style if they intend to launch their own academic journal in future.

Furthermore, the instructor of the course got actively involved in the class and explained some important points missed out by the presenters. Some of the presenters created multiple illustrations during the presentation using the software, the instructor had given valuable comments on the improvement of the illustrations and improved some of the illustrations himself as a practical demonstration of a better learning of the students.

\section{Students performance evaluation strategies}

The class emphasized a training component, but also include interactive lectures, discussion groups, and assessments at the instructor's discretion. In all sessions, both formative and summative assessments were used by the instructor. Grades followed the standard BUCT grading policy published in the syllabus and provided to students prior to the course.

The instructor and students agreed that teaching in a classroom is best suited to this course. This course not only served as an information transfer but also stimulated creative and critical thinking; therefore, questions and answers flowed in both directions between instructor and students.

The summative assessment included the already designed manuscript assessment for reviewing and focused group discussion on a bigger canvas than minor details such as grammatical errors and misspellings. The title and the keywords of the manuscript were removed prior to distributing the manuscripts among the students. Eighteen different manuscripts were distributed among the students to ensure that all group members actively participate and make a different analysis, which facilitated a sharp comparison of the writing. 
Furthermore, this format facilitated focused group discussions, optimizing the use of time, providing an equal opportunity for all members to share their opinion and avoiding one person taking control of all the group discussion.

The readers of the manuscript having different experience and skill level provide their input from their manuscript drafts. Each participant has actively contributed in writing comments. All the group members working on one draft were asked to give detailed comments while avoiding redundancy or repetition. Every member of the group was encouraged to give new comments. The group leader was responsible for keeping the group members on task ensure each person's timely feedback. It is important to note that all participants have been given sufficient time to contribute to the assignment.

The students were asked to "Enlist a minimum of two manuscript strengths and weaknesses" such as novelty and scope. The participants were encouraged to start with highlighting the positive points of the manuscript to enhance their ability to suggest improvements.

The second question was to "Enlist at least two specific ways to strengthen the manuscript." This question received diverse answers which helped in keeping the focus on the bigger canvas including clarity, flow, and organization, instead of pointing out minor mistakes. However, the students were encouraged to point out redundancy in the manuscript, which made it difficult to read. For instance, if the writer of the manuscript continuously lacks the logic and has poorly organized the sections or paragraphs, this could be marked as a major element which needs improvement.

The last question asks students, "To point out the single most important item to be focused on for revision?" It helps to determine whether the manuscript is rejected out rightly rather than getting an acceptance for revision and resubmission. The assignment was concluded with the summary of the main points of the group discussion, confirming that the writer of the manuscript was given sufficient guidance about their next steps in the revision process. This assignment has helped to enhance the overall effectiveness of the course.

\section{Evaluating the effectiveness of the course}

Since it is the first time to implement this course and there is less literature available to enable the teacher to apply models to evaluate the effectiveness of the course. This paper provided a guideline and useful information to its readers to further build on the effectiveness of academic writing courses. However, two parameters were used to assess the value of AAWS, the first was the attendance of the students who regularly attended the course in the given year. Results showed that $90 \%$ of the students attended the classes. High attendance rate and a very low rate of students quitting the course indicated that the course has not only attracted but retained many students. Another parameter applied in this study was satisfaction of this course. The effectiveness of the course was further confirmed by employing satisfaction point, an evaluation index is given by the participants of the course, based on their own opinions. The evaluation indicators were taken from the previous study (Chen, Zhao, \& Wang, 2016). The indicators have been modified for relevance for the current research. Specific evaluating indicators are shown in Table 2. 
Table 2. The Evaluating Indicator of Satisfaction Points

\begin{tabular}{|c|c|c|}
\hline No. & Evaluating Indicator & Weight \\
\hline 1 & $\begin{array}{l}\text { I have learnt a lot from this course, understood and mastered the main } \\
\text { content taught by the teacher. I can troubleshoot writing problems in the } \\
\text { already designed manuscript }\end{array}$ & 0.2 \\
\hline 2 & Teacher was confident and passionate while teaching this course & 0.1 \\
\hline 3 & Teacher has prepared well for this course; lectures were understandable & 0.1 \\
\hline 4 & $\begin{array}{l}\text { Assignments were designed meticulously, and instructor paid enough } \\
\text { attention to analyzing scientific writing problems. This course had } \\
\text { provided the students an effective model for becoming a more meticulous } \\
\text { revisionist of their own writing }\end{array}$ & 0.2 \\
\hline 5 & Teaching methodology was appropriate & 0.1 \\
\hline 6 & $\begin{array}{l}\text { Communication inside and outside the class was effective, and students } \\
\text { were highly encouraged to share their opinion }\end{array}$ & 0.1 \\
\hline 7 & Students were taught in accordance with their aptitudes & 0.1 \\
\hline 8 & This course helped to promote critical thinking & 0.1 \\
\hline
\end{tabular}

Each indicator has 5 options, A for 95 points, B for 85 points, C for 75 points, D for 60 points, and $\mathrm{E}$ for 50 points. The total points were then obtained according to the weight and grade. All students were asked to give their own evaluation anonymously, the final score was calculated to be $95 \%$ by using weight and grade. Finally, three indications have been given, the first was the successful accomplishment of this course. The second indication was that the students mastered the basic concepts of AAWS and they can meticulously review their own manuscripts prior to submission. The third indication was that it enhanced the research productivity and lowered the chance of the manuscript rejection. The students were also provided the opportunity to provide free-text comments to the course. Some of the comments are as follows:

(1) The course has provided us the unique opportunity to develop hand on software skills, which we would not have learned otherwise. It is important to note, that the volunteer presenters who presented on the use of different softwares had first learned using them and then delivered presentations.

(2) The course has encouraged us to develop critical thinking.

(3) The course has enabled us to become more meticulous researchers and writers and gave us new directions of brainstorming prior to getting started with the manuscript or any other technical writing.

Others did offer some suggestions:

(1) We would have been more comfortable in taking the course if it was offered in the beginning (first year of Ph.D. and Master). It would have helped us to enhance our research productivity earlier.

(2) It would have helped us a lot more if we were given a little background document/reading materials to read prior to the course. 


\section{Conclusion}

Results indicated that the implemented course is successful. This course offered a series of positive adjustments in the academic writing skills of young researchers and scientists at BUCT to improve the quality of research, education, and publication. The instructor provided the students with courage and expression ability, reinforced their confidence, taught them initiating the technical writing, and increased their self-learning ability. This study provided international students connecting with OBOR, a brief exposure to the art of writing an impressive manuscript. Most of the students who have studied the course were from Pakistan and other OBOR countries, who could further disseminate the contents of AAWS to improve scientific writing skills and educational performances in their respective countries. The most important outcome of the study was provision of an opportunity to OBOR countries to improve experience exchange, teaching cooperation, and education communication. Furthermore, the results offered a model to other universities or majors to bring adjustments for the improvement of the academic writing skills of research scholars in China and worldwide.

\section{Acknowledgement}

This study was supported by the Teaching Reform Program in Graduate Education at Beijing University of Chemical Technology (G-JG-PT201603) and "One Belt, One Road" National Talent Training Project of Beijing, China.

\section{References}

Casañ-pitarch, R., \& Calvo-ferrer, J. R. (2015). Developing writing skills in the classroom: A corpus-based analysis of multi-genre structures. Procedia-Social and Behavioral Sciences, 198, 74-83. https://doi.org/10.1016/j.sbspro.2015.07.421

Chen, C., Zhao, C., \& Wang, B. (2016). Teaching reform in biochemistry-facing the Washington accord and engineering accreditation. Education Journal, 5(4), 75-80. https://doi.org/10.11648/j.edu.20160504.16

Eaton, S. E. (2017). Perceptions of ESL program management in Canadian Higher Education : A qualitative case study. International Journal of Learning, Teaching and Educational Research, 16(9), 13-28. https://doi.org/doi.org/10.26803/ijlter.16.9.2

Ejdys, J. (2017). New Silk Road-a weak or a strong signal? Procedia Engineering, 182, 182-188. https://doi.org/10.1016/j.proeng.2017.03.159

Klimova, B. F. (2013). Developing thinking skills in the course of academic writing. Procedia-Social and Behavioral Sciences, 93, 508-511. https://doi.org/10.1016/i.sbspro.2013.09.229

Langum, V., \& Sullivan, K. P. H. (2017). Writing academic English as a doctoral student in Sweden: narrative perspectives. Journal of Second Language Writing, 35, 20-25. https://doi.org/10.1016/j.jslw.2016.12.004

Marsden, M. (2017). Actually existing silk roads. Journal of Eurasian Studies, 8(1), 22-30. https://doi.org/10.1016/i.euras.2016.11.006

Morton, P. G. (2013). The importance of being published. Journal of Professional Nursing, 29(4), 187-188. https:// doi.org/10.1016/i.profnurs.2013.06.011

Moussa-inaty, J. (2017). Student experiences of a blended learning environment. International Journal of Learning, Teaching and Educational Research, 16(9), 60-72. https://doi.org/doi.org/10.26803/ijlter.16.9.5

Ness, V., Duffy, K., Mccallum, J., \& Price, L. (2014). Getting published: Reflections of a 
collaborative writing group. Nurse Education Today, 34(1), 1-5. https://doi.org/10.1016/j.nedt.2013.03.019

Rakedzon, T., \& Baram-tsabari, A. (2017). To make a long story short: A rubric for assessing graduate students' academic and popular science writing skills. Assessing Writing, 32, 28-42. https://doi.org/10.1016/i.asw.2016.12.004

Sheu, J. B., \& Kundu, T. (2017). Forecasting time-varying logistics distribution flows in the One Belt-One Road strategic context. Transportation Research Part E, 1-18. https://doi.org/dx.doi.org/10.1016/j.tre.2017.03.003

Uçar, S., \& Yazıcı, Y. (2016). The impact of portfolios on enhancing writing skills in ESP classes. Procedia-Social and Behavioral Sciences, 232, 226-233.

https://doi.org/10.1016/j.sbspro.2016.10.001 